\title{
Effects of sub-grid variability of precipitation and canopy water storage on climate model simulations of water cycle in Europe
}

\author{
D. Wang ${ }^{1}$, E. N. Anagnostou ${ }^{1,2}$, and G. Wang ${ }^{1}$ \\ ${ }^{1}$ Department of Civil and Environmental Engineering, University of Connecticut, Storrs, CT, USA \\ ${ }^{2}$ Institute of Inland Waters, Hellenic Center for Marine Research, Anavissos, Greece
}

Received: 15 January 2008 - Revised: 1 June 2008 - Accepted: 30 June 2008 - Published: 29 July 2008

\begin{abstract}
The impact of sub-grid variability of precipitation and canopy water storage is investigated over Central-South Europe by applying a new canopy interception scheme into the Community Atmosphere Model (CAM, Version 3) coupled with the Community Land Model (CLM, Version 3). The study shows that while sub-grid variability exerts great impact on the land surface water budget, the impact on the atmospheric hydrological processes is small and only exception being the Mediterranean region. In this region, incorporation of sub-grid variability is shown to reduce precipitation up to $1 \mathrm{~mm} /$ day (or $\sim 8 \%$ relative to mean precipitation). The evapotranspiration ratio (ratio of evapotranspiration to total precipitation) exhibited insignificant deviations between the simulations with sub-grid variability and the ones without, which indicates that the local source of moisture is not the cause of the reduced precipitation. On the other hand, inducing sub-grid variability alters the large-scale circulation, which transports less water vapor form Atlantic Ocean to inland areas thus reducing precipitation in the Mediterranean region.
\end{abstract}

\section{Introduction}

Precipitation is arguably the most important component in manipulating land-atmospheric interactions. The realistic representation of flux exchanges between land surface and atmosphere in global climate models (GCMs) relies not only on the accuracy of simulated precipitation amounts, but also on the realistic precipitation intensity at resolutions finer than the typical resolution of GCMs. Several studies have considered the sub-grid scale variability of precipitation in GCMs (give references). A recent study by Wang and Wang (2007)

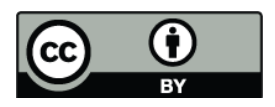

Correspondence to: E. N. Anagnostou manos@ath.hcmr.gr presented a new hydrology scheme that accounts for the subgrid variability of both precipitation and vegetation canopy water storage on the basis of the method presented by Shuttleworth (1988). This scheme is robust under different model temporal resolutions (Wang and Wang, 2007), and has been validated against field measurements of vegetation canopy interception over the globe (Wang et al., 2007a) using the Community Land Model (CLM-Oleson et al., 2004) in its stand-alone mode.

The impact of sub-grid variability of precipitation and canopy water storage feeds back from land surface to the atmosphere through the flux exchanges. Wang et al. (2008) investigated this impact by applying the new canopy hydrology scheme into the coupled CLM-Community Atmosphere Model (CAM), with focus the tropics. In this paper, we extend the investigation in mid-latitudes to study the impact on water and energy budgets over Central-South Europe using the same method as in Wang et al. (2008). In the subsequent section we shortly describe the model, while in Sects. 3 and 4 we discuss our simulation results and conclusions.

\section{Model description}

The Community Atmosphere Model version 3 (CAM3) (Collins et al., 2004) and the Community Land Model version 3 (CLM3) (Oleson et al., 2004), which are respectively the atmosphere component and land surface component of the NCAR Community Climate System Model version 3 (CCSM3), are used in this study. CAM3 is designed to completely separate the physical parameterizations from the dynamic core. While three dynamic cores (i.e., Eulerian spectral, semi-Lagrangian and finite volume) are available in CAM3, the Eulerian spectral dynamic core is used in this study. CLM3 considers the sub-grid variability of land surface properties by using a four-level data structure from higher to lower level: grid cells, land units (i.e., glacier, lake,

Published by Copernicus Publications on behalf of the European Geosciences Union. 
Table 1. Comparison between the experiment simulation (EXP) and the control simulation (CTL) in water and energy balance on land surface over the Central-South Europe $\left(7^{\circ} \mathrm{W}-25^{\circ} \mathrm{E}, 37^{\circ} \mathrm{N}-55^{\circ} \mathrm{N}\right)$ for June-July-August (JJA) and December-January-February (DJF). All the variables are domain average. DIFF=EXP-CTL, and NDIFF $(\%)=100 \% \times(\mathrm{EXP}-\mathrm{CTL}) / \mathrm{CTL}$.

\begin{tabular}{|c|c|c|c|c|c|c|c|c|}
\hline & \multicolumn{4}{|c|}{ JJA } & \multicolumn{4}{|c|}{ DJF } \\
\hline & CTL & EXP & DIFF & NDIFF & CTL & EXP & DIFF & NDIFF \\
\hline Precipitation $\left(\mathrm{mm} \cdot \mathrm{day}^{-1}\right)$ & 1.64 & 1.52 & -0.12 & -7.3 & 2.92 & 2.68 & -0.23 & -8.0 \\
\hline Runoff $\left(\mathrm{mm} \cdot \mathrm{day}^{-1}\right)$ & 0.36 & 0.39 & 0.03 & 8.3 & 0.96 & 0.91 & -0.05 & -5.0 \\
\hline Interception loss $\left(\mathrm{mm} \cdot \mathrm{day}^{-1}\right)$ & 0.55 & 0.34 & -0.21 & -38 & 0.44 & 0.25 & -0.19 & -43 \\
\hline Plant transpiration $\left(\mathrm{mm} \cdot \mathrm{day}^{-1}\right)$ & 0.52 & 0.60 & 0.08 & 15 & 0.035 & 0.04 & 0.005 & 14 \\
\hline Incident solar radiation $\left(\mathrm{W} \cdot \mathrm{m}^{-2}\right)$ & 250.5 & 251.9 & 1.4 & 0.6 & 48.5 & 49.7 & 1.16 & 2.4 \\
\hline Incident longwave radiation $\left(\mathrm{W} \cdot \mathrm{m}^{-2}\right)$ & 341.1 & 341.2 & 0.1 & 0.03 & 311.2 & 308.6 & -2.55 & -0.8 \\
\hline Sensible heat flux $\left(\mathrm{W} \cdot \mathrm{m}^{-2}\right)$ & 64.9 & 66.5 & 1.6 & 2.5 & -27.2 & -23.4 & 3.8 & 14 \\
\hline Latent heat flux $\left(\mathrm{W} \cdot \mathrm{m}^{-2}\right)$ & 56.9 & 54.9 & -2.0 & -3.5 & 37.3 & 33.7 & -3.62 & -10 \\
\hline Vegetation temperature $(\mathrm{K})$ & 293.6 & 293.8 & 0.2 & 0.07 & 279.6 & 279.3 & -0.3 & -0.1 \\
\hline Ground temperature $(\mathrm{K})$ & 294.5 & 294.6 & 0.1 & 0.03 & 279.5 & 279.1 & -0.4 & -0.1 \\
\hline
\end{tabular}

a) CTL (JJA) 1.64

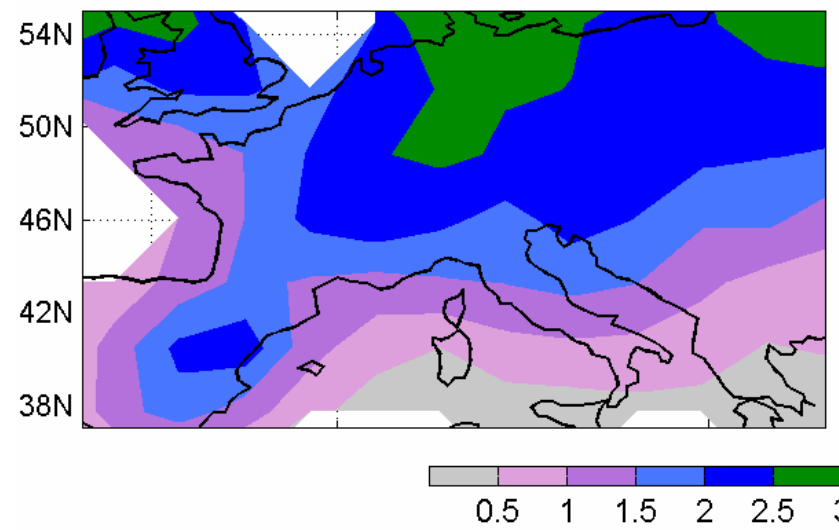

c) CTL (DJF) 2.92

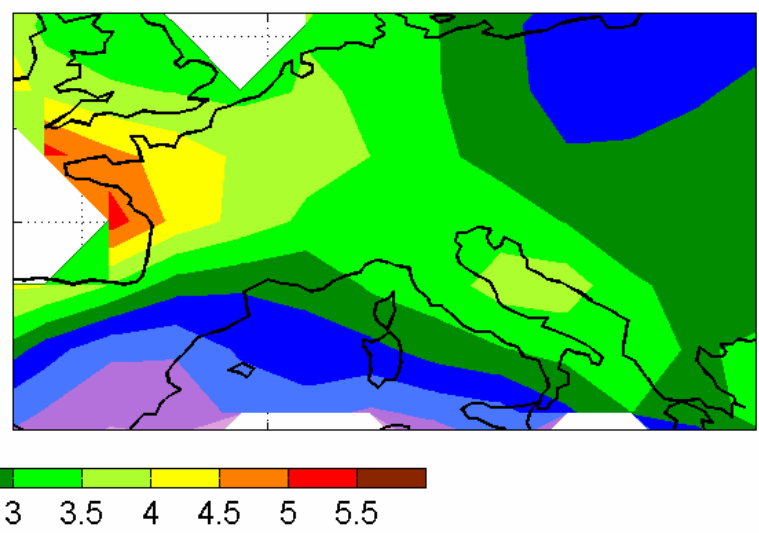

b) EXP-CTL (JJA) -0.12

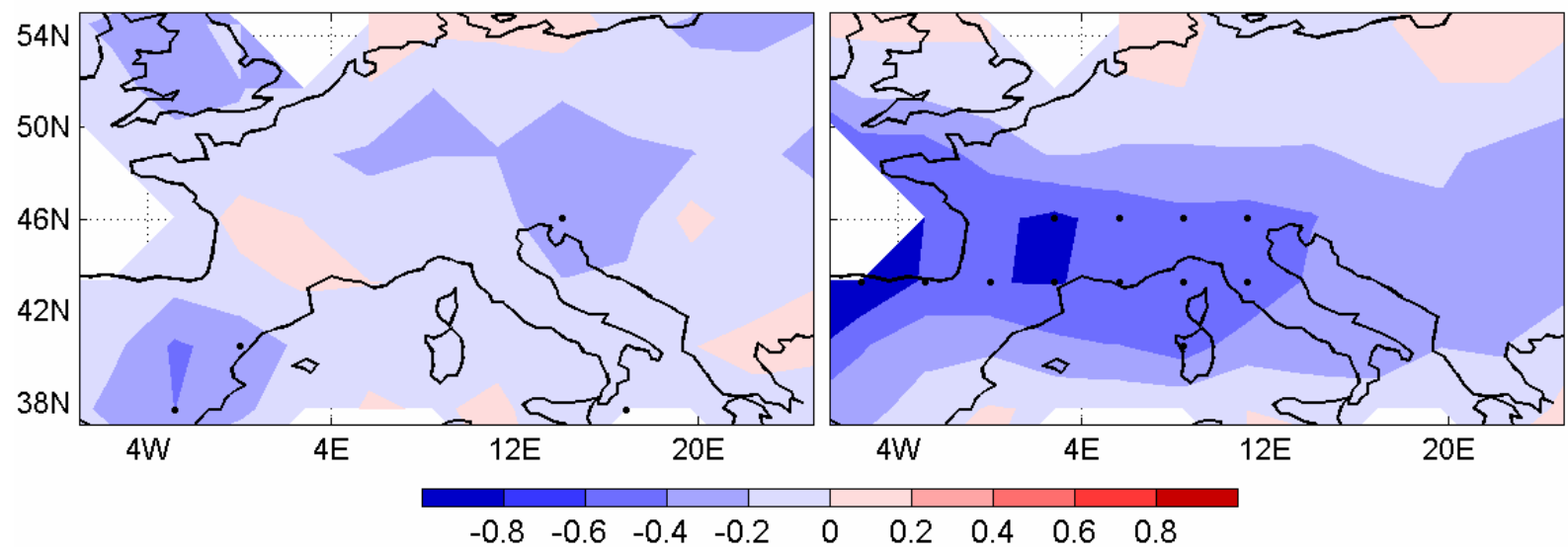

Fig. 1. Precipitation simulated in CTL and the EXP-CTL difference for June-July-August (JJA) and December-January-February (DJF) over the Central-South Europe (in $\mathrm{mm} \cdot \mathrm{day}^{-1}$ ). The numbers shown on the titles are regional averages. The stipples show areas where the differences shown in (b) and (d) pass the 10\% significance test (or 90\% confidence level). 
a) CTL 0.49
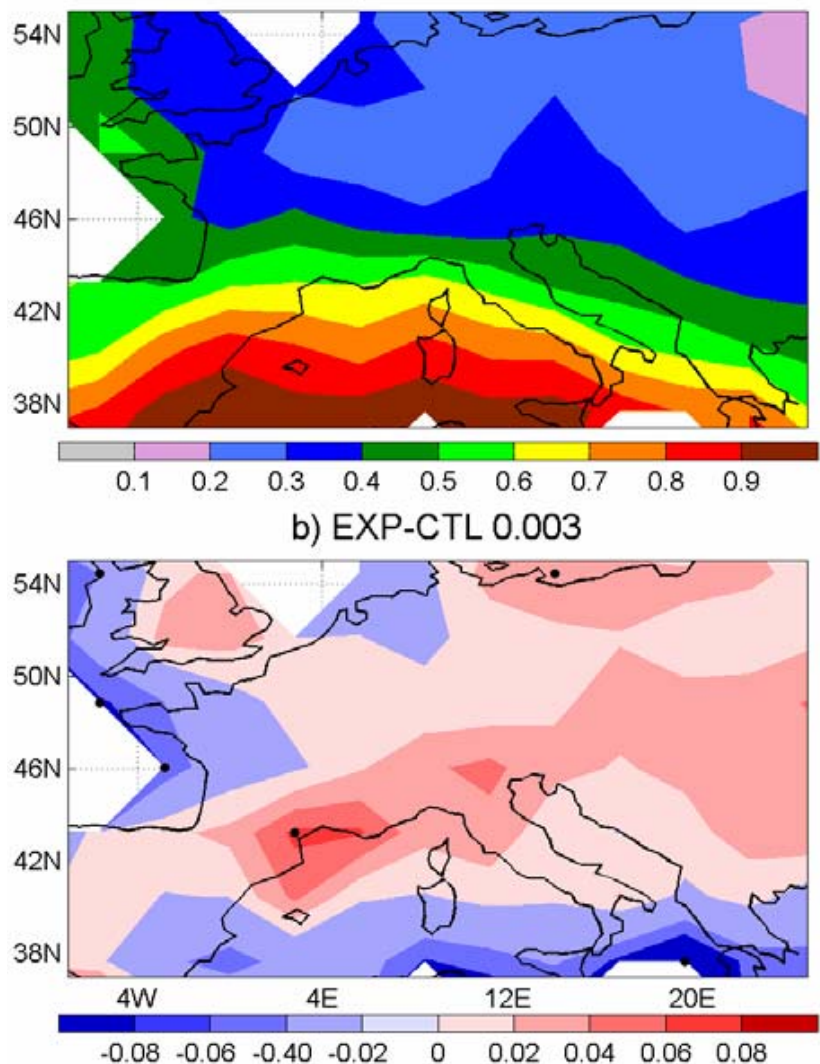

Fig. 2. Evapo-transpiration ratio (ratio of evapo-transpiration to precipitation) simulated in CTL and the EXP-CTL difference over the Central-South Europe for DJF. The numbers in the titles are regional averages. The stipples show areas where the differences pass the $10 \%$ significance test.

wetland, urban, and vegetated), and snow/soil columns, plant functional types (PFTs). However, since the atmospheric forcing is simulated by CAM3, CLM3 is driven by gridaveraged precipitation, temperature, surface pressure, wind velocity, humidity, and radiation. Among the various components of atmospheric forcing, precipitation in reality shows the strongest sub-grid variability. In the publicly available version of CLM3, the grid-averaged precipitation, together with vegetation density, determines the rate of water intercepted by vegetation canopy:

$I c=P_{m}[1-\exp (-0.5(L A I+S A I))]$

where $I c$ is the canopy interception rate, $P_{m}$ is the gridaveraged precipitation intensity (simulated by atmosphere models or derived from reanalysis data), $L A I$ is the one-sided leaf area index, $S A I$ is the one-sided stem area index. Canopy dripping $D r$ occurs when canopy water storage $S$ exceeds the water holding capacity $C$.

This formulation is commonly used in current land surface models (e.g., Simple Biosphere Model (Shellers et al., 1986, a) CTL

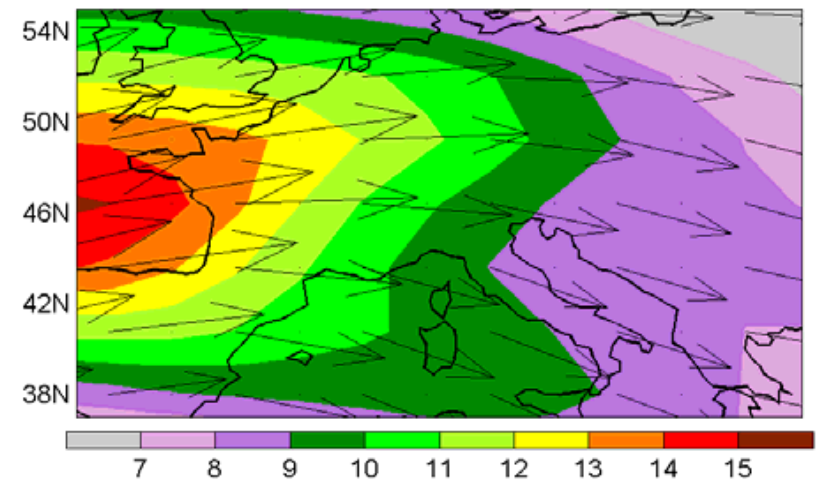

b) EXP-CTL

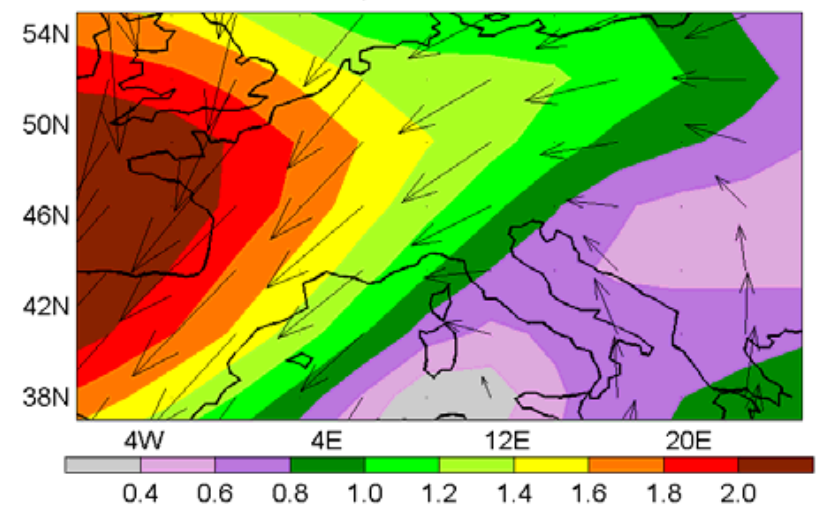

Fig. 3. The $850 \mathrm{mb}$ mean wind velocity (in $\mathrm{m} / \mathrm{s}$ ) simulated in CTL and the EXP-CTL differences for DJF. Arrows show flow directions.

1996), and has been demonstrated to dramatically overestimate interception loss (loss of precipitation due to evaporation of intercepted water) over the Amazon basin (Dickinson and Henderson-Sellers, 1988). Wang and Wang (2007) proposed a canopy interception scheme that considers the subgrid variability of both precipitation and canopy water storage based on the dynamic-statistical approach proposed by Shuttleworth (1988). Validation against observations at various sites over the globe demonstrated that the offline CLM3 with this scheme performs much better than the publicly available version of CLM3 (Wang et al., 2007a). This newly proposed canopy interception scheme is briefly described here. More details can be found in Wang and Wang (2007) and Wang et al. (2007a). The canopy interception rate for two different portions of each model grid cell is estimated separately as follows:

$\left\{\begin{array}{l}I c_{\text {rainc }}-D r_{\text {rainc }}=\left(\frac{P_{c}}{\mu}+P_{l}\right)\left(1-\exp \left(-\frac{I_{\text {max, rainc }}}{P_{c}+P_{l}}\right)\right) \text { rain areas } \\ I c_{\text {norainc }}-D r_{\text {norainc }}=P_{l}\left(1-\exp \left(-\frac{I_{\text {max,norainc }}}{P_{l}}\right)\right) \text { no rain areas }\end{array}\right.$

where the subscript "rainc" stands for the convective raincovered area, the subscript "norainc" stands for the remaining area, $I c$ is the canopy interception rate, $D r$ is the dripping 
rate, $P_{c}$ is the convective rain rate, $P_{l}$ is the stratiform rain rate, $I_{\max }$ is the maximum canopy infiltration rate, and $\mu$ is the convective rain coverage fraction and is estimated as the ratio of the grid average convective rainfall intensity to the observed conditional mean convective rain rate (Eltahir and Bras, 1993).

\section{Simulation results}

The two canopy hydrology schemes described in Sect. 2 were applied to the coupled CAM3-CLM3. The impact of subgrid variability on hydrological processes was investigated by comparing the simulations with these two schemes. In the first type of simulations (labeled as CTL), the publicly available version of CAM3-CLM3 is used. Precipitation and canopy water storage is treated to be spatially uniform according to Eq. (1). In the second type of simulations (labeled as EXP), the sub-grid variability of precipitation and canopy water storage is considered in the canopy hydrology parameterization according to Eq. (2). CAM3-CLM3 is run for 18 years with prescribed climatological, monthly-varying sea surface temperature for these two types of simulations. The first 3 years are discarded as spinup, and the last 15 years is taken for analysis.

The impact of sub-grid variability starts from altering precipitation intercepted by vegetation canopy, leading to the change of water budget on the land surface (Wang et al., 2005, 2006 and 2008). The changes of land surface water budget feeds back to atmosphere through landatmospheric flux exchanges. Table 1 shows the regional averages of hydrological variables simulated in CTL and EXP and their differences over the Central-South Europe during summer (June-July-August, JJA) and winter season (December-January-February, DJF). In general, the sub-grid variability exerts more impact on the hydrological processes during winter (DJF) relative to the summer (JJA) season. The difference in interception loss is the most significant of all parameters given that the newly developed scheme changes the interception loss directly. The change in interception loss from CTL to EXP alters the heat fluxes from land surface to atmosphere, which leads to the difference in precipitation through feedback mechanisms. Figure 1 shows precipitation simulated in CTL and the EXP-CTL differences during JJA and DJF over the Central-South Europe. While Wang et al. (2008) have shown that including the sub-grid variability (EXP simulation scenario) increases precipitation over the tropics, this study shows the opposite (i.e. precipitation reduction) over most areas of the Central-South Europe. However, this reduction is not found to be statistically significant at $90 \%$ confidence level (or $10 \%$ exceedance probability), except in the Mediterranean region where the reduction is shown to be up to $1 \mathrm{~mm} /$ day during winter season. Figure 2 shows the simulated ET ratio (ratio of ET to precipitation) in CTL and EXP-CTL differences for this region in the winter season. Although the interception loss ratio (ratio of interception loss to precipitation) is dramatically reduced (not shown here) from CTL to EXP due to inclusion of sub-grid variability in the model, the ET ratio is shown to increase only by a small percentage (2-5\%). Therefore, the local moisture fluxes may not be the major source for the precipitation reduction shown in Fig. 1. Figure 3 on the other hand shows the wind field at 850 mbar level during the winter season. It is evident that including the sub-grid variability weakens the large-scale circulation in the Mediterranean region during the winter months. Consequently, less water vapor is transported from the surrounding ocean in EXP, therefore reducing precipitation.

\section{Conclusions}

In this paper, we investigated the impact of sub-grid variability of precipitation and canopy water storage in the CentralSouth Europe by applying a new canopy interception scheme to CAM3-CLM3. Taking the precipitation as an example, the impact was not found statistically significant at $90 \%$ confidence level over most areas of Europe except the Mediterranean region. The reduction in this region is up to $1 \mathrm{~mm} /$ day, which is about $8 \%$ reduction relative to simulated precipitation. Investigating the causes of this reduction in precipitation, we noted that the ET ratio (ratio of ET to total precipitation) exhibits a small increase (2-5\%) between the simulation with sub-grid variability and the one without, which indicates that the local source of moisture may not be the main cause of the reduced precipitation. On the other hand, including the sub-grid variability was shown to change the large-scale circulation patterns, which weaken (10-12\%) the transport of water vapor from Atlantic Ocean to the Mediterranean region, with consequential effects on precipitation.

Acknowledgements. This work was supported by EU Marie Curie Excellence Grant project PreWEC (MEXT-CT-2006-038331).

Edited by: A. Mugnai

Reviewed by: one anonymous referee 


\section{References}

Dickinson, R. E. and Henderson-Sellers, A.: Modeling tropical deforestation: A study of GCM land surface parameterizations, Q. J. Roy. Meteorol. Soc., 114, 439-462, 1988.

Dickinson, R. E., Oleson, K. W., Bonan, G., et al.: The community land model and its climate statistics as component of the community climate system model, J. Climate, 19, 2302-2324, 2006.

Eltahir, E. A. B. and Bras, R. L.: Estimation of the fractional coverage of rainfall in climate models, J. Climate, 6, 639-644, 1993.

Sellers, P. J., Mintz, Y., Sud, Y. C., and Dalcher, A.: A simple biosphere model ( $\mathrm{SiB})$ for use within General Circulation Models, J. Atmos. Sci., 43, 505-531, 1986.

Sellers, P. J., Randall, D. A., Collatz, G. J., Berry, J., Field, C., Dazlich, D. A., Zhang, C., Collelo, G. D., and Bounoua, L.: A revised land surface parameterization $(\mathrm{SiB} 2)$ for Atmospheric GCMs. Part 1: model formulation, J. Climate, 9, 676-705, 1996.

Shuttleworth, W. J.: Macrohydrology-The new challenge for process hydrology, J. Hydrol., 100, 31-56, 1988.

Wang, D. G., Wang, G. L., and Anagnostou, E. N.: Use of satellitebased precipitation observation in improving the parameterization of canopy hydrological processes in land surface models, J. Hydrometeorol., 6, 745-763, 2005.
Wang, D. G., Anagnostou, E. N., and Wang, G. L.: The effect of sub-grid rainfall variability on the water balance and flux exchange processes resolved at climate scale: The European region contrasted to Central Africa and Amazon rainforests, Adv. Geosci., 7, 269-274, 2006,

http://www.adv-geosci.net/7/269/2006/.

Wang, D. G. and Wang, G. L.: Towards a robust canopy hydrology scheme with precipitation sub-grid variability, J. Hydrometeorol., 8, 439-446, 2007.

Wang, D. G., Wang, G. L., and Anagnostou, E. N.: Evaluation of canopy interception scheme in Land surface models, J. Hydrol., 347, 308-318, 2007a.

Wang, G. L. and Eltahir, E. A. B.: Impact of rainfall sub-grid variability on modeling the biosphere-atmosphere system, J. Climate, 13, 2887-2899, 2000.

Wang, D. G., Wang, G. L., and Anagnostou, E. N.: Impact of sub-grid variability of precipitation and canopy storage on atmosphere hydrological processes, J. Climate, in press, 2008. 